\title{
Comparison of Low dose oral Methotrexate vs Systemic Corticosteroids for treatment of Oral Lichen Planus
}

\author{
TOOBA SAEED ${ }^{1}$, SAADIA FIRDOUS², SHAHZAD IQBAL MALIK³ ${ }^{2}$ MUHAMMAD AAMIR ${ }^{4}$, YASIR ISHAQ ${ }^{5}$, NABEELA RIAZ ${ }^{6}$ \\ ${ }^{1}$ Assistant Professor Dept. of Oral \& Maxillofacial Surgery, University College of Medicine and Dentistry, The University of Lahore \\ ${ }^{2}$ Assistant Professor Dept. of Oral \& Maxillofacial Surgery, Avicenna Dental College, Lahore \\ ${ }^{3}$ Senior Registrar Dept. of Oral \& Maxillofacial Surgery, King Edward Medical University/ Mayo Hospital Lahore \\ ${ }^{4}$ Senior Registrar Dept. of Oral \& Maxillofacial Surgery, Gaiju Khan Medical College Swabi \\ ${ }^{5}$ Assistant Professor Dept. of Oral \& Maxillofacial Surgery, Akhtar Saeed Medical and Dental College, Lahore \\ ${ }^{6}$ Professor/ HOD Dept. of Oral \& Maxillofacial Surgery, King Edward Medical University/ Mayo Hospital Lahore \\ Correspondence to Dr. Tooba Saeed, Email: tooba.saeed@ucd.uol.edu.pk, Cell: 03344243905, H.No. 23/16 Khalid St. Islamia Park Lahore
}

\begin{abstract}
Background: Oral Lichen Planus (OLP) is a relatively common chronic inflammatory mucocutaneous disorder. WHO considers OLP a premalignant lesion. This makes management of OLP important to avoid its malignant transformation. Corticosteroids are considered as the first-line of treatment. Different other treatment modalities are also in use for OLP. But there is no statistically significant data available for a particular therapy. The recent evidences suggest methotrexate may effectively be used in low dose in the treatment of OLP.

Aim: To compare the frequency of complete resolution of mucosal lesions of oral lichen planus with low dose oral methotrexate versus systemic corticosteroids.

Methods: It was a randomized control trial conducted at Oral \& Maxillofacial Surgery Department, King Edward Medical University/Mayo Hospital Lahore in six months. A sample of 60 patients was divided into two sub groups namely Group -A (methotrexate) and Group - B (corticosteroid) using lottery method. More than $75 \%$ resolution of mucosal lesions clinically was considered as complete resolution at the end of 8th week.

Results: The mean age of the patients was $44.55 \pm 12.38$ years. On 8th week, frequency of complete resolution of mucosal lesions was $73.3 \%$ in Group A and $60 \%$ in Group B with an insignificant difference ( $p$-value $<0.05$ ).

Conclusion: Methotrexate group A showed more complete resolution of mucosal lesions than corticosteroid group B with insignificant statistical difference.

Keywords: Oral Lichen Planus, Mucosal lesions, Malignant transformation, Methotrexate, Corticosteroids
\end{abstract}

\section{INTRODUCTION}

Oral Lichen Planus (OLP) is a chronic inflammatory, noninfectious mucocutaneous disorder which affects approximately $1-2 \%$ of general population ${ }^{1}$ which includes $1.57 \%$ females and $0.96 \%$ males $^{2}$. Clinically OLP have been classified as reticular, papular, plaque like, atrophic, erosive and bullous forms ${ }^{1,3}$. Usually OLP presents in bilateral symmetrical mannar. Most common sites of involvement include buccal mucosa, dorsum of the tongue, gingivae and vermilion of lower lip. The lesion is usually painless but atrophic, bullous and erosive lesions are associated with pain and burning sensation ${ }^{3,4}$. The precise cause of OLP is unknown but it is supposed to be an autoimmune disorder of T-lymphocytes (CD-8). These Tlymphocytes identify self-antigen on keratinocytes resulting in inflammation and keratinocyte cell death ${ }^{1,3,4}$. The diagnosis of OLP is based on history, clinical findings and histopathology ${ }^{1}$. Various drugs such as corticosteroids, retenoids, cyclosporins, dapson, griseofulvin, hydroxychloroquine, tacrolimus and thalidomide have been used alone or in combination orally, parentally or topically for treatment of symptomatic OLP ${ }^{4,5}$. A number of studies in the last decade showed that rate of malignant transformation in OLP varies from $0 \%$ to $5.3 \%$. OLP has been consider as a precancerous condition according to World Health Organization, which is "a generalized state associated with a significant increased risk of cancer ${ }^{6}$.

Received on 23-12-2020

Accepted on 13-04-2021
Different treatments have been used in literature for OLP. But the management of OLP is always a challenge for physician either due to chronic and refractory nature of the disease, or lack of strong evidence available for different treatment modalities. Meanwhile, spontaneous remission is also a strong contributory factor in judgment of treatment effectiveness ${ }^{7}$.

The purpose of this study is to compare the two treatment modalities for OLP and evaluate their effectiveness. Since no study helps us decide if Methotrexate, a cost-effective drug, can replace corticosteroids in treatment of OLP and thus preventing the side effects of corticosteroids and at the same time treating OLP effectively. In this study we compare the frequency of complete resolution of mucosal lesions of oral lichen planus with low dose oral Methotrexate vs. systemic corticosteroids.

\section{METHODS}

This Randomized clinical trialwas conducted in the Department of Oral \& Maxillofacial Surgery, King Edward Medical University / Mayo Hospital Lahore from June 2014 to November 2014. Sampling technique wasnon-probability purposive sampling.Sample size of 60 cases (30 in each in each group) was calculated with $80 \%$ power of test, $5 \%$ level of significance and taking expected percentage of complete resolution of mucosal lesion in both groups i.e. $75 \%$ in low dose oral methotrexate group versus $40.9 \%$ in systemic corticosteroid group for the treatment of OLP. 
Inclusion criteria was 1) Age of the patient between 18 years to 70 years. 2) Patients of both genders. 3) Patients with clinically diagnosed oral lichen planus (bilaterally symmetrical pattern, pain, burning sensation).4) Patients on other therapies that failed to control the OLP. However, patients with HIV, hepatitis $B$ and $C$ diagnosed on medical records (screening with ELISA) and $\mathrm{Hb}<9 \mathrm{mg} / \mathrm{dl}$ were excluded. Also the lactating mothers and pregnant patients diagnosed on history and who expected to be pregnant within three months of treatment were excluded from the study.

Ethical Approval was taken prior to conduction of the study. All patients presented at Oral \& Maxillofacial Surgery Department Mayo Hospital Lahore and meeting the inclusion criteria were included in this study. Informed consent of the patient was taken for performing examination, taking photographs and obtaining biopsies if required for scientific and educational purposes and publication of these materials wherever required, after explaining the expected outcome of both treatment regimes. Patients were randomly divided into two groups by lottery method. Patient's demographic details including name, age, gender and contact information was recorded. Group A (Methotrexate) was given $15 \mathrm{mg}$ oral methotrexate per week in a single dose together with $1 \mathrm{mg}$ folic acid daily except for the day of methotrexate administration for 8 weeks. Group B (Corticosteroid) was given 50mg/day prednison orally plus nilstat drops for 8 weeks. Patients were recalled for follow up on 1 st, 2nd, 4th, and finally on 8th week for assessment of frequency of complete resolution of mucosal lesions of OLP. More than $75 \%$ resolution of mucosal lesions clinically was considered as complete resolution.

Statistical analysis: Data was entered \& analyzed by using SPSS version 25.0. Mean and Standard deviation were calculated for quantitative variables like age. Frequencies and percentages were computed for categorical variables such as; complete resolution of mucosal lesions. Both the groups were compared for the frequency of complete resolution of mucosal lesions of OLP using a chi-square test ( $P$ value $\leq 0.05$ as significant). Data was stratified for the variables like age ( $>40, \leq 40$ years) and type of OLP i.e. more aggressive types(erosive, bullous, atrophic) or less aggressive types(reticular, plaque like, popular) to address the effect modifiers.

\section{RESULTS}

There were total 60 patients who were divided in two equal group i-e 30 each treatment groups. The mean age of patients in Group A was $44.66 \pm 13.03$ with minimum and maximum age was 22 and 66 years, whereas mean age of patients in Group B was $44.43 \pm 11.93$ ranges from 26 to 64 years. Majority of the patients were female with frequency and percentage of $41(68.3 \%)$. Frequency and percentage of male patients in both the groups were $8(26.7 \%)$ and $11(36.7 \%)$ respectively whereas frequency and percentages of female in both the groups were $22(73.3 \%)$ and $19(63.3 \%)$ respectively. On 8th week, complete resolution of mucosal lesions was assessed, in which $22(73.3 \%)$ patients have complete resolution of mucosal lesions in Group A and In Group B 18(60\%) patient got complete resolution of mucosal lesions (Table I). Chisquare was used to compare the frequency of complete resolution of mucosal lesions in both groups, which was statistically not significant ( $p$-value 0.412 ), which shows that there is no significant difference in frequency of complete resolution of mucosal lesions in patients of oral lichen planus treated with low dose methotrexate and in patients treated with corticosteroids.

Later on the data was stratified for age and type of lesions to check the impact of effect modifiers on the resolution of OLP. There was non-significant difference between age group of $<40$ or $>40$ years for the resolution of the OLP (Table II). Furthermore, non-significant difference found between types of lesion and groups for the resolution of the OLP (Table III).

Table I: Comparison of complete resolution in both treatment

\begin{tabular}{|c|c|c|c|}
\hline \multirow{2}{*}{$\begin{array}{l}\text { Complete } \\
\text { Resolution of } \\
\text { Mucosal Lesion }\end{array}$} & \multicolumn{2}{|c|}{ Two groups } & \multirow{2}{*}{ Total } \\
\hline & $\begin{array}{c}\text { Group A } \\
\text { (methotrexate) }\end{array}$ & $\begin{array}{c}\text { Group B } \\
\text { (corticosteroid) }\end{array}$ & \\
\hline Yes & $22(73.3 \%)$ & $18(60 \%)$ & $40(66.66 \%$ \\
\hline No & $8(26.7 \%)$ & $12(40 \%)$ & $20(33.33 \%)$ \\
\hline Total & $30(100 \%)$ & $30(100 \%)$ & $60(100 \%)$ \\
\hline
\end{tabular}

value 0.412

Table II: Stratification with respect to age

\begin{tabular}{|l|l|l|l|l|l|}
\hline \multirow{2}{*}{ Age group } & $\begin{array}{l}\text { Complete resolution of } \\
\text { OLP }\end{array}$ & $\begin{array}{l}\text { Group A } \\
\text { Methotrexate }\end{array}$ & $\begin{array}{l}\text { Group B } \\
\text { Corticosteroids }\end{array}$ & Total & P-value \\
\hline \multirow{2}{*}{ More than 40 years } & Yes & $9(52.9 \%)$ & $8(47.1 \%)$ & $17(100 \%)$ & 1.000 \\
\cline { 2 - 7 } & No & $8(47.1 \%)$ & $9(52.9 \%)$ & $17(100 \%)$ & \\
\hline Total & & $17(50 \%)$ & $17(50 \%)$ & $34(100 \%)$ & \\
\hline \multirow{2}{*}{40 years or less } & Yes & $13(100 \%)$ & $10(76.9 \%)$ & $23(88.5 \%)$ & \multirow{2}{*}{0.220} \\
\cline { 2 - 7 } & No & 0 & $3(23.1 \%)$ & $3(11.5 \%)$ & $26(100 \%)$ \\
\hline Total & & $13(100 \%)$ & $13(100 \%)$ & & 2 \\
\hline
\end{tabular}

Table 3: Stratification with respect to type of lesions

\begin{tabular}{|l|l|l|l|l|l|}
\hline \multirow{2}{*}{ Type of OLP } & $\begin{array}{l}\text { Complete Resolution } \\
\text { of OLP }\end{array}$ & $\begin{array}{l}\text { Group A } \\
\text { Methotrexate }\end{array}$ & $\begin{array}{l}\text { Group B } \\
\text { (Corticosteroids) }\end{array}$ & Total & p-value \\
\hline \multirow{2}{*}{ Less aggressive type } & Yes & $15(83.3 \%)$ & $15(62.5 \%)$ & $30(71.4 \%)$ & 0.180 \\
\cline { 2 - 6 } & No & $3(16.7 \%)$ & $9(37.5 \%)$ & $12(28.6 \%)$ & $42(70 \%)$ \\
\hline Total & & $18(100 \%)$ & $24(100 \%)$ & $10(55.6 \%)$ & 1.000 \\
\hline \multirow{2}{*}{ More aggressive type } & Yes & $7(58.3 \%)$ & $3(50 \%)$ & $8(44.4 \%)$ & $18(100 \%)$ \\
\cline { 2 - 7 } & No & $5(41.7 \%)$ & $3(50 \%)$ & $6(100 \%)$ & $18(2 \%)$ \\
\hline
\end{tabular}




\section{DISCUSSION}

In spite of elaborate research and vast experimentation that has been going on in the last decade and a half regarding various aspects of treating Oral Lichen Planus still controversy has not been far away. Incomplete understanding of the exact etiology and pathogenesis of Oral Lichen Planus and its differentiation from lichenoid reactions thrive controversy in treatment. But owing to its malignant potential continues research is going on regarding new and better treatment modalities. CTs are till date the first line therapy for OLP. Our study was also aimed at comparing oral low dose methotrexate (MTX) with systemic corticosteroids (CTs) in patients suffering from Oral Lichen Planus. However, some recent studies are investigating methotrexate (MTX) for management of OLP $8,9,10$

Low dose Methotrexate is a drug of choice in the treatment of rheumatoid arthritis (RA), an autoimmune chronic inflammatory disease. Furthermore, Low dose Methotrexate is also used in other chronic inflammatory diseases like psoriasis, SLE, GVHD, inflammatory bowel disease ${ }^{11,12}$.

It is a documented fact that females are more commonly affected by OLP than male ${ }^{13,14}$. In our study a total of 60 patients were enrolled. It consisted of $68.3 \%$ female and $31.6 \%$ male patients, with female to male ratio of $2.2: 1$. These results are in accordance with literature where female to male ratio is $2: 1^{15}$. Kaplan et al. (2012) also revealed $F$ : $M$ ratio of $2.4: 1$ in his study of 171 patients ${ }^{2}$. However in some studies female to male sex predilection of $4: 1$ was also reported ${ }^{13}$.

The mean age of our patients was $44.66 \pm 13.03$ years in Group A, whereas in Group B age was 44.43 11.93 . These value were close to the national as well as international figures in studies by: Qazi $\mathrm{JA}^{13}$, Javadzadeh $\mathrm{A}$ et $\mathrm{al}^{16}$ and Salem $\mathrm{G}^{17}$ who reported mean ages as 48 years, 48.3 years and 49 years respectively. But, these values are lower than the values of study conducted by Kaplan et al; mean age $59.1 \pm 12.4^{2}$ and Lozada-Nur et al(18) who found mean age to be 60 years. Predominantly adults over 40 years are affected with OLP, however it can occur in children also ${ }^{20}$.

We measured outcome in terms of complete resolution of mucosal lesions and we considered more than $75 \%$ disappearance of mucosal lesions clinically as complete resolution. On 8th week, complete resolution of mucosal lesions was assessed, in which 22(73.3\%) patients have complete resolution of mucosal lesions in methotrexate Group A and in prednisone Group B, $18(60 \%)$ patients got complete resolution of mucosal lesions. Dorothea C. Torti et al (2007) in their study declared low-dose methotrexate as an agent with substantial activity in OLP. In their study, they revealed that greater than $75 \%$ improvement of OLP occurred in $56 \%$ of patients receiving methotrexate ${ }^{4}$. This percentage is relatively lower than our results of $73.3 \%$ complete resolution. Another study revealed that combination of low dose methotrexate and triamcinolone is a better treatment modality in Oral lichen planus ${ }^{19}$.
Many studies reported the effective role of low dose methotrexate in generalized LP. Sachan et al accepted beneficial role of methotrexate as first line treatment. He compared oral methotrexate with oral prednisone. In methotrexate group $93.33 \%$ patient showed complete response. While $73.33 \%$ patient showed complete response in predinisone group. Although the adverse effects were not seen in both groups but 5 patients presented with relapse in prednisone group as compared to methotrexate group where no relapse was seen ${ }^{20}$. Lunge et al compared the low dose methotrexate with low molecular weight heparin for the treatment of generalized LP. He also observed specifically the response of oral lesions in these patients. Better complete response $85 \%$ was recorded in methotrexate group with very little relapse as compared to heparin group ${ }^{21}$. Similarly Eknath more et al also revealed oral methotrexate as reliable treatment for generalized LP, exhibiting low recurrence and adequate safety in hypertensive and diabetic patients. But delayed onset of action is a major disadvantage of methotrexate treatment ${ }^{9}$.

Furthermore, A.J. Kanwar in their prospective study revealed 14 of $24(58 \%)$ patients had complete remission of their disease after 24 weeks treatment with low-dose oral methotrexate $\left(15 \mathrm{mg} /\right.$ week) in generalized lichen planus ${ }^{22}$. Similarly, Farhad Malekzad (2011) also used low dose oral methotrexate in generalized lichen planus. He observed $12(75 \%)$ had excellent improvement and 3 patients (18.7\%) had mild improvement at the end of the 8th week. While one patient was insensitive to treatment even after 8 weeks ${ }^{10}$. This study is in accordance with our study, as the results were concluded at the end of 8 th week. Overall $75 \%$ of patients showed excellent improvement which is also comparable to our results i.e., $73.3 \%$.

HakanTuran, (2008) initiated methotrexate at two different dosages. First as a single oral dose of 15 $\mathrm{mg} /$ week in four patients and second as $20 \mathrm{mg} /$ week in seven patients. He observed Improvement of mucocutaneous lesions and pruritus in all patients within the first month, irrespective of dose. In 10 patients at the end of the first month complete response was attained ${ }^{8}$.

We also stratified data for type of OLP i.e. more aggressive types (erosive, bullous, atrophic) or less aggressive types (reticular, plaque like, papular). In literature less aggressive type also known as white forms and more aggressive type as red forms. In our study white form was predominated $70 \%$ versus the red form $30 \%$ of the cases. These results are close to the results of corbane study, where white form was $43(66 \%)$ while red form was $34 \%$ of the cases $(n=22)$. In contrast to these results, BirsayGümrü observed white form in $39.5 \%$ of the cases (146 patients), and red forms in 60.5\% (224 patients) in his series $^{23,24}$.

Hazra SC (2013) compared the adverse outcome of methotrexate and mini pulse betamethasone while treating the patients of LP. He concluded on the basis of clinical and laboratory parameters that methotrexate group $A$ showed relatively less adverse effects than betamethasone group B. Thus, methotrexate can be used as an alternative safe drug therapy for the treatment of lichen planus ${ }^{25}$.

The present knowledge about treatment of OLP is as low dose oral methotrexate a superior drug in literature as 
compared to systemic corticosteroids whereas our study did not find any statistically significant difference in the outcome of the two drugs. Still we are in favor of low dose oral methotrexate as a treatment of OLP because of its less adverse effects and less chance of disease relapse as revealed by different studies of generalized LP. But further studies specifically in OLP with more variables, more time, longer follow ups and a greater number of patients are warranted before any conclusion about superiority of one drug over the other can be ascertained and a definite first line drug therapy may be adopted.

\section{CONCLUSION}

Etiopathogenesis of Oral Lichen Planus needs to be understood to ascertain a definite drug therapy. The treatment of OLP remains controversial and vast. Different treatment modalities are under scrutiny and research is ongoing. The potential for malignant transformation of the disease warrants investigation and needs close follow up in addition to aggressive therapy. This study found statistically insignificant difference in the outcome of low dose oral methotrexate versus systemic corticosteroids in treatment of OLP but a greater percentage of patients benefitted from methotrexate as compared to corticosteroids. However, large scale, multicenter, randomized, clinical comparative trials may be done to prove their treatment response.

Author contribution: TS: Idea, study plan, execution, preparation of final draft, SF: Collection of data, data analysis, SIM: Writing discussion, final review, MA: Literature review, YI: Data analysis, review of final draft and NR: Final draft critical review

Limitations of the study: The major limitation of this study is that it was a single centered study representing specific group of population. We suggest large scale studies with more variables and longer follow ups to prove treatment response of different treatment modalities in OLP.

Competing interest/Funding source: There is no conflict of Interest and funding source.

Disclosure Statement: This article is based on data collected for dissertation, approved by College of Physician and Surgeon.

Acknowledgement: The authors acknowledge the staff of Oral \& Maxillofacial unit at Mayo Hospital who helped in follow-up visits of patients suffering from OLP.

\section{REFERENCES}

1. Boorghani $M$, Gholizadeh N, TaghaviZenouz A, Vatankhah $M$, Mehdipour M. Oral lichen planus: clinical features, etiology, treatment and management; a review of literature. J Dent Res Dent Clin Dent Prospects. 2010 Winter;4(1):3-9. doi: 10.5681/joddd.2010.002.

2. Kaplan I, Ventura-Sharabi Y, Gal G, Calderon S, Anavi Y. The dynamics of oral lichen planus: a retrospective clinicopathological study. Head Neck Pathol. 2012;6(2):178-83 doi: 10.1007/s12105-0110318-3.

3. Srinivas K, Aravinda K, Ratnakar P, Nigam N, Gupta S. Oral lichen planus-Review on etiopathogenesis. Natl J Maxillofac Surg. 2011;2(1):15. doi: 10.4103/0975-5950.85847

4. Torti DC, Jorizzo JL, McCarty MA. Oral lichen planus: a case series with emphasis on therapy. Arch Dermatol. 2007;143(4):511-5. doi: 10.1001/archderm.143.4.511.

5. Lodi G, Scully C, Carrozzo M, Griffiths M, Sugerman PB, Thongprasom K. Current controversies in oral lichen planus: report of an international consensus meeting. Part 2. Clinical management and malignant transformation. Oral Surg Oral Med Oral Pathol Oral Radiol. 2005;100(2):164-78. doi: 10.1016/j.tripleo.2004.06.076

6. Ismail SB, Kumar SK, Zain RB. Oral lichen planus and lichenoid reactions: etiopathogenesis, diagnosis, management and malignant transformation. J Oral Sci.2007;49(2):89-106. doi: 10.2334/josnusd.49.89

7. Husein-ElAhmed $H$, Gieler $U$, Steinhoff $M$. Lichen planus: a comprehensive evidence-based analysis of medical treatment. J Eur Acad Dermatol Venereol. 2019;33(10):1847-62. doi: 10.1111/jdv.15771.

8. Turan H, Baskan EB, Tunali S, Yazici S, Saricaoglu H. Methotrexate for the treatment of generalized lichen planus. J Am Acad Dermatol. 2009;60(1):164-6. doi: 10.1016/j.jaad.2008.09.054.

9. More YE, Khatu SS, Chavan DC, Mahajan P, Pawar S, Gokhale N. Evaluation of safety and efficacy of low-dose methotrexate as an alternative treatment option to systemic corticosteroids in generalized lichen planus. Med J DY Patil Univ. 2017;10(2):149.doi: 10.4103/09752870.202094

10. Malekzad F, Saeedi M, Ayatollahi A, Beheshti S, Tajish S. Low dose Methotrexate for the treatment of generalized lichen planus. Iran $\mathrm{J}$ Dermatol 2012; 14:131-5

11. Giavedoni P, Mascaró J, Rovira M, Fernández-Avilés F, Gutiérrez G, Rosiñol L, Suarez-Lledó M, Martínez C. Safety and efficacy of lowdose methotrexate for the treatment of refractory sclerodermatous chronic graft-versus-host disease: a single institution retrospective study: P217. Bone Marrow Transplant. 2017;52.

12. Lucas CJ, Dimmitt SB, Martin JH. Optimising low-dose methotrexate for rheumatoid arthritis-A review. $\mathrm{Br} J$ Clin Pharmacol. 2019;85(10):2228-34.doi:10.1111/bcp.14057

13. Qazi JA. Treatment of oral lichen planus with topical tacrolimus and triamcinolone acetonide ointment - A comparative study. Pak. Oral Dent. 2010;30(1):19-22.

14. Al-Hashimi I, Schifter M, Lockhart PB, Wray D, Brennan M, Migliorati $\mathrm{CA}$, et al. Oral lichen planus and oral lichenoid lesions: diagnostic and therapeutic considerations. Oral Surg Oral Med Oral Pathol Oral Radiol, and Endod. 2007;103:S25-31. doi:10.1016/j.tripleo.2006.11.001

15. Laeijendecker R, Tank B, Dekker SK, Neumann HA. A comparison of treatment of oral lichen planus with topical tacrolimus and triamcinolone acetonide ointment. Acta Derm Venereol.2006;86(3):227-9.doi: 10.2340/00015555-0070

16. Javadzadeh A, Vatanpour H, Delavarian Z, Momajed A, Esmaeily H, Vatanpour M, et al. Efficacy of Clobetasol, Ketoconazole and Amitryptiline Mouthwash on oral lichen planus. Iran J Pharm Res. 2010;7(3): 171-178. doi: 10.22037/ijpr.2010.762

17. Salem G. Oral lichen planus among 4277 patients from Gizan, Saudi Arabia. Community Dent Oral Epidemiol.1989;17(6):322-4. doi: 10.1111/j.1600-0528.1989.tb00647.x.

18. Lozada-Nur Fl, Sroussi HY. Tacrolimus powder in orabase $0.1 \%$ for the treatment of oral lichen planus and oral lichenoid lesions: an open clinical trial. Oral Surg Oral Med Oral Pathol Oral Radiol Endod.2006;102(6):744-9. doi: 10.1016/j.tripleo.2006.02.033.

19. Chauhan P, De D, Handa S, Narang T, Saikia UN. A prospective observational study to compare efficacy of topical triamcinolone acetonide $0.1 \%$ oral paste, oral methotrexate, and a combination of topical triamcinolone acetonide $0.1 \%$ and oral methotrexate in moderate to severe oral lichen planus. Dermatol Ther. 2018 ;31(1). doi: $10.1111 /$ dth. 12563

20. Sachan S, Chaudhary SS, Prateek K, Jose M. A prospective study comparing therapeutic efficacy and safety of oral methotrexate and oral prednisone in the treatment of generalized cutaneous lichen planus. J Dent Med Sci. 2017;16:143-7.doi: 10.9790/0853160502143147

21. Lunge S, Patil S, Manjunathswamy B. A comparative study of methotrexate \& low molecular weight heparin for the treatment of generalized lichen planus. Indian J Clin Exp Dermatol. 2016; 2:1538.doi: $10.18231 / 2455-6769.2016 .0007$

22. Kanwar AJ, De D. Methotrexate for treatment of lichen planus: old drug, new indication. J Eur Acad Dermatol Venereol.2013;27(3):e4103.doi: 10.1111/j.1468-3083.2012.04654.x.

23. Torrente-Castells E, Figueiredo R, Berini-Aytés L, Gay-Escoda C. Clinical features of oral lichen planus. A retrospective study of 65 cases. Med Oral Patol Oral Cir Bucal. 2010 ;15(5):e685-90. doi: 10.4317/medoral.15.e685.

24. Gümrü B. A retrospective study of 370 patients with oral lichen planus in Turkey. Med Oral Patol Oral Cir Bucal. 2013;18(3):e427. doi:10.4317/medoral.18356

25. Hazra SC, Choudhury AM, Asaduzzaman AT, Paul HK. Adverse outcome of methotrexate and mini pulse betamethasone in the treatment of lichen planus. Bangladesh Med Res Counc Bull. 2013;39(1):22-7. doi: 10.3329/bmrcb.v39i1.15806. 